\title{
ANÁLISE FITOQUÍMICA DAS CASCAS E DO MIOLO DA RAIZ DE URERA BACCIFERA (L.) GAUDICH (URTICACEAE)
}

\author{
Amanda Leitão Gindri; Michele da Silva**; Marília Buss de \\ Marchi*; $^{* *}$ Lucas Scherer Brum ${ }^{* *}$; Margareth Linde Athayde ${ }^{* * *}$; \\ Solange Cristina da Silva Martins Hoelze/****
}

RESUMO: Urera baccifera (L.) Gaudich, conhecida popularmente como Urtiga-brava, ocorre desde a América Central até a Argentina. Testes farmacológicos já mostraram a atividade analgésica e antiinflamatória de extratos aquosos desta planta em ratos, no entanto não há registros na literatura de seus constituintes químicos. 0 objetivo deste trabalho foi realizar uma análise fitoquímica da raiz de Urera baccifera. Os resultados dos metabólitos doseados no extrato bruto das raízes foram: polifenóis totais: $29,76+1,5 \mathrm{mg} / \mathrm{g}$ de extrato, flavonóides: $16,42+0,1 \mathrm{mg} / \mathrm{g}$ de extrato; taninos condensados: $19,11+0,77 \mathrm{mg} / \mathrm{g}$ de extrato e alcalóides totais: $1,58+0,02 \mathrm{mg} / \mathrm{g}$ de extrato. No teste de capacidade antioxidante frente ao radical DPPH a planta deste estudo obteve um valor de $\mathrm{IC}_{50} 188,57 \mathrm{mg} / \mathrm{g}$ de extrato. Os testes qualitativos aplicados nos extratos da casca e no miolo da raiz apresentaram resultados positivos para heterosídeos flavonoídicos e purinas apenas na casca, heterosídeos saponínicos apenas no miolo e taninos e mucilagens na casca e no miolo da raiz. Estes resultados estão sendo descritos pela primeira vez para esta planta.

Descritores: Urera baccifera; Polifenóis totais; Alcalóides; Flavonóides; Taninos; Antioxidante.

\section{PHYTOCHEMICAL ANALYSIS OF THE STEAM AND THE CORE OF THE ROOT FROM URERA BACCIFERA (L.) GAUDICH (URTICACEAE)}

ABSTRACT: Urera baccifera (L.) Gaudich popularly known as Nettle, occurs from Central America to Argentina. Pharmacological tests have shown the analgesic and anti-inflammatory effect of aqueous extract of this plant in rats, however there aren't records in literature of their chemical constituents. The objective of this work was the phytochemical analysis of the root of Urera baccifera. The results of the metabolites assayed in the crude extract of the roots were: total phenolics: $29.76+1.5 \mathrm{mg} / \mathrm{g}$ of plant extract; flavonoids: $16.42+0.1 \mathrm{mg} / \mathrm{g}$ of plant extract; condensed tannins: $19.11+0.77 \mathrm{mg} / \mathrm{g}$ of extract and alkaloids: $1.58+0.02 \mathrm{mg} / \mathrm{g}$ extract. In the test of antioxidant capacity against the DPPH radical, the plant of this study obtained an $\mathrm{IC}_{50}$ value of $188.57 \mathrm{mg} / \mathrm{g}$ of extract. The qualitative assays showed positive results for flavonoids and purines in the stem root, saponins only in the core and tannins and mucilage in the both parts of the root. These results are been described for the first time to this plant.

Descriptors: Urera baccifera; Nettle; Phenolic compounds; Alkaloids; Flavonoids; Condensed tannins; Antioxidant capacity.

\footnotetext{
*Aluna do Curso de Pós-Graduação em Ciências Farmacêuticas da UFSM. Santa Maria - RS, Brasil.

${ }^{* *}$ Graduados em Farmácia pelo Centro Universitário Franciscano, Santa Maria - RS, Brasil

***Professora adjunta da Universidade Federal de Santa Maria, Santa Maria - RS, Brasil.

${ }^{* * * *}$ Professora adjunta do Centro Universitário Franciscano, Santa Maria - RS, Brasil
} 


\section{Introdução}

Tão antigo quanto a espécie humana, o uso de plantas para o tratamento e cura de enfermidades ocorre ainda hoje desde as regiões mais pobres do país até as grandes cidades brasileiras. As plantas com uso medicinal são comercializadas em feiras livres, mercados populares e encontradas em quintais residenciais ${ }^{1}$.

À família Urticaceae pertencem plantas predominantemente herbáceas, contendo pêlos urticantes em certos gêneros, dentre eles Urtica e Urera². Urera baccifera (L.) Gaudich, planta conhecida popularmente como urtiga-brava ou urtigão, é utilizada pela população para diversas condições inflamatórias através de infusão ou uso tópico, possuindo também um efeito rubefaciente usado em dores reumáticas ${ }^{3}$.

Este tipo de arbusto lenhoso ocorre desde a América Central até a Argentina, incluindo a região andina. Estudos realizados com o extrato aquoso de U. baccifera mostraram a atividade analgésica e anti-inflamatória em ratos. Outras espécies da família Urticaceae apresentaram efeitos antiviral, hipoglicemiante e atividade cardiovascular, no entanto, não há registros na literatura de seus constituintes químicos ${ }^{4}$.

O presente trabalho teve como objetivos a realização de doseamento de polifenóis totais, flavonóides, taninos condensados e alcalóides, bem como a avaliação da capacidade antioxidante frente ao radical DPPH do extrato bruto da raiz e uma análise fitoquímica das cascas e do miolo das raízes de $U$. baccifera, visando uma pesquisa preliminar das substâncias presentes na planta, o que leva a acrescentar mais conhecimentos sobre esta espécie tão pouco estudada e bastante utilizada popularmente nesta região.

\section{Material e métodos}

\section{Coleta e extração do material vegetal:}

As raízes da planta Urera baccifera foram coletadas no município de Santa Maria, em agosto de 2007. Para a obtenção do extrato bruto, uma parte das raízes $(500 \mathrm{~g})$ foi seca em estufa de ar circulante, triturada em moinho de pás e colocada em maceração com solvente hidroalcóolico (etanol:água 70:30), numa concentração de $30 \mathrm{~g} / \%$, com agitação diária e renovação do solvente semanalmente, por 4 semanas. Para a obtenção dos extratos de casca e miolo da raiz para a análise fitoquímica, essas foram separadas manualmente, secas em estufa de ar circulante e trituradas em moinho de pás. Após este processo as cascas $(2,971 \mathrm{~g})$ e o miolo $(2,986 \mathrm{~g})$ foram submetidas à extração em aparelho de Soxhlet utilizando etanol $95^{\circ} \mathrm{GL}$ como solvente. Após resfriado, o extrato hidroalcóolico foi concentrado em rotavapor à temperatura de $40^{\circ} \mathrm{C}$.

\section{Avaliação da capacidade antioxidante:}

Para a avaliação da capacidade antioxidante foi utilizado o método colorimétrico do DPPH (2,2-difenil-1-picril-hidrazil), segundo Choi e colaboradores (2002) $)^{5}$, onde a amostra foi avaliada

Saúde (Santa Maria), v.36, n.2, p. 63-70, jul./dez. 2010. Análise fitoquímica qualitativa das cascas e do miolo da raíz de urera baccifera (l.) gaudich (urticaceae) nas concentrações $250,125,62,5,31,25,15,62$ e $7,81 \mu \mathrm{g} / \mathrm{mL}$. 0 ensaio foi realizado em triplicata e a porcentagem de inibição do radical DPPH calculada através da equação 1 , descrita a seguir: 
$\%$ inibição $=100-[($ Abs. da amostra - Abs. do branco $) \times 100]$

Abs. do controle

Equação 1 - Cálculo da porcentagem de inibição. Onde: Abs. da amostra é a absorbância do extrato bruto; Abs. do branco é a absorbância extrato bruto sem adição do DPPH e Abs. controle é a absorbância da solução de DPPH em etanol.

Após os cálculos foi construído um gráfico contendo a porcentagem de inibição versus concentração do extrato e calculada a equação da reta, que foi utilizada para o cálculo do $\mathrm{IC}_{50}$ (concentração efetiva para obter $50 \%$ de atividade antioxidante da planta frente ao radical $\mathrm{DPPH})$.

\section{Determinação de polifenóis totais}

O conteúdo de polifenóis totais foi avaliado através do método colorimétrico descrito por Chandra e Mejia $(2004)^{6}$, que utiliza o reagente Folin Ciocalteau 2N, leitura em espectrofotômetro à $730 \mathrm{~nm}$ e a amostra na concentração de $0,150 \mathrm{mg} / \mathrm{mL}$, diluída em etanol e em triplicata. $O$ teor de polifenóis totais foi calculado através da confecção de curva analítica de calibração utilizando o ácido gálico como referência em um intervalo de concentração de 0,001 a $0,03 \mathrm{mg} / \mathrm{mL}$

\section{Determinação de flavonóides}

O doseamento de flavonóides foi realizado conforme o método colorimétrico descrito por Woisky e Salatino (1998) 7 . Esta metodologia utiliza uma solução de cloreto de alumínio $2 \%$ e leitura em espectrofotômetro a $420 \mathrm{~nm}$. As amostras foram preparadas na concentração de $0,150 \mathrm{mg} / \mathrm{mL}$, em triplicata. Para o cálculo do teor de flavonóides foi utilizada uma curva de calibração de quercetina no intervalo de 2 a $18 \mu \mathrm{g} / \mathrm{mL}$.

\section{Determinação de taninos condensados}

A determinação de taninos condensados seguiu o método colorimétrico descrito por Morrison e colaboradores $(1995)^{8}$, o qual utiliza uma solução de ácido clorídrico 8\% e uma solução de vanilina $1 \%$. A amostra foi preparada na concentração de $25 \mathrm{mg} / \mathrm{mL}$ e a leitura realizada em $500 \mathrm{~nm}$. 0 ensaio foi realizado em triplicata e para o teor de taninos condensados foi utilizada uma curva de calibração com catequina no intervalo de 2,5 a $200 \mathrm{mg} / \mathrm{mL}$.

\section{Determinação de Alcalóides totais}

Para o doseamento de alcalóides totais foi utilizada a metodologia de Oliveira e colaboradores $(2006)^{9}$ a qual emprega o reagente de Dragendorff e tiouréia, e leitura em espectrofotômetro em $435 \mathrm{~nm}$. A amostra foi preparada na concentração de $60 \mathrm{mg} / \mathrm{mL}$ e o teste foi realizado em triplicata. Para o cálculo do teor de alcalóides foi utilizada uma curva analítica com nitrato de bismuto, no intervalo de 0,01 a 0,09 mg/mL.

\section{Análise fitoquímica qualitativa}

A análise fitoquímica qualitativa da casca e do miolo das raízes foi realizada conforme metodologias descritas em publicações especializadas ${ }^{10}$, seguindo uma série de reações de caracterização, tais como: gomas (reação de precipitação com ácido acidulado, reação com acetato de chumbo e reação com cloreto férrico); mucilagens (índice de entumescimento); heterosídeos cardiotônicos (núcleo esteroidal: reação de Liebermann-Buchard; anel lactônico

Saúde (Santa Maria), v.36, n.2, p. 63-70 jul./dez. 2010

Gindri, A. L.; Silva, M.; Marchi, M. B.; Brum, L. S.; Athayde, M. L.; Hoelzel, S. C. S. ISSN 2236-5843 
pentagonal: reação de Kedde e reação de Baljet; glicona, presença de açúcares e desoxiaçúcares: reação de Keller-Killiani e reação de Xantidrol); heterosídeos antraquinônicos (reação de Borntraiger e pesquisa do tipo de ligação); heterosídeos flavonoídicos (reação de Shinoda e reação com hidróxidos alcalinos); heterosídeos saponínicos (determinação do índice de espuma); taninos (reação com sais de ferro, reação com acetato de chumbo, reação com gelatina e reação com acetato de cobre); alcalóides (reações de Dragendorf, Meyer e Bertrand) e purinas (reação da murexida).

\section{Resultados e Discussões}

No teste de capacidade antioxidante frente ao radical DPPH foi obtido um $\mathrm{IC}_{50}$ de $188,57 \mathrm{mg} / \mathrm{g}$. Este valor evidencia uma modesta capacidade antioxidante do extrato bruto das raízes, o que é confirmado por Martins e colaboradores (2006) ${ }^{11}$, que testaram o extrato etanólico e as frações nhexano, diclorometano, acetato de etila e n-butanol dos galhos desta planta, sendo obtido uma boa atividade antioxidante para as frações diclorometano e acetato de etila $(37,05$ e $57,30 \mathrm{~g} / \mathrm{ml}$ respectivamente) e uma baixa atividade antioxidante para os outros extratos (>1000 g/ml). Entretanto, Mannion e Menezes (2010) ${ }^{12}$, analisando o extrato etanólico das partes aéreas de $U$. baccifera e partições deste em hexano, diclorometano, acetato de etila e n-butanol, obtiveram como melhor valor de capacidade antioxidante frente ao $\mathrm{DPPH}$, um $\mathrm{EC}_{50}=120,16 \mathrm{mg} / \mathrm{g}$ na fração em acetato de etila, classificando esta atividade como alta.

Os resultados obtidos para os doseamentos de polifenóis totais, flavonóides, taninos condensados e alcalóides estão expressos na Tabela 1, juntamente com a equação da reta obtida com cada substancia química de referencia e seu coeficiente de correlação.

Tabela 1 - Resultados obtidos no doseamento de polifenóis totais, flavonóides, taninos condensados e alcalóides para a raiz de Urera baccifera

\begin{tabular}{cccc}
\hline Teste & Resultado $(\mathrm{mg} / \mathrm{g})+\mathrm{DP}^{*}$ & Equação da Reta & Coeficiente de correlação (R) \\
\hline Polifenóis totais & $29,76+1,5$ & $\mathrm{y}=30,767 x-0,0087$ & 0,9992 \\
Flavonóides & $16,42+0,1$ & $y=0,0402 x+0,001$ & 0,9998 \\
Taninos condensados & $19,11+0,77$ & $y=0,0015 x+0,0005$ & 0,9968 \\
Alcalóides totais & $1,58+0,02$ & $y=2,2783 x+0,0361$ & 0,9997 \\
\hline
\end{tabular}

*DP= Desvio padrão da média

Os valores obtidos para polifenóis totais e flavonóides neste estudo foram semelhantes aos descritos por Mannion e Menezes (2010) ${ }^{12}$ nas partes aéreas de $U$. baccifera, uma vez que coincidem com o intervalo de valores obtidos para as diferentes partições efetuadas por estes autores. Já os valores obtidos para taninos condensados e alcalóides, por serem descritos pela primeira vez na espécie, não permitiram uma comparação direta com outros autores. Após a quantificação dos polifenóis totais, flavonóides, taninos condensados e alcalóides no extrato

Saúde (Santa Maria), v.36, n.2, p. 63-70, jul./dez. 2010. Análise fitoquímica qualitativa das cascas e do miolo da raíz de urera baccifera (l.) gaudich (urticaceae) bruto da raiz, foi realizada a analise fitoquímica comparativa para verificar se havia diferença qualitativa na composição dos extratos da casca e do miolo da raiz da planta.

$U$. baccifera apresentou resultados positivos para heterosídeos flavonoídicos e purinas apenas na casca, heterosídeos saponínicos apenas no miolo e taninos e mucilagens na casca e no miolo da raiz. A tabela 2 apresenta os resultados obtidos nos testes. 
Tabela 2 - Resultados obtidos para cada classe de metabólito nas duas partes da raíz.

\begin{tabular}{ccc}
\hline Testes & Casca & Miolo \\
\hline Gomas & - & - \\
Mucilagens & + & + \\
Heterosídeos cardiotônicos & - & - \\
Heterosídeos antraquinônicos & - & - \\
Heterosídeos flavonoídicos & + & - \\
Heterosídeos saponínicos & - & + \\
Taninos & + & - \\
Alcalóides & - & - \\
Purinas & + &
\end{tabular}

Em análise fitoquímica preliminar, os resultados negativos não implicam necessariamente na ausência dos metabólitos secundários na parte da planta, podendo ocorrer que a quantidade dos mesmos esteja pequena para sua deteç̧ão por reações qualitativas ${ }^{13} .0$ baixo valor encontrado no doseamento de alcalóides totais (Tabela I) e a ausência de resultado positivo nos testes de alcalóides totais (Tabela II) corroboram esta afirmação.

Chaurasia e Wichtl (1987) $)^{14}$ isolaram flavonóides glicosilados nas flores da Urtica dióica (Urticaceae), planta da mesma família de U. baccifera. Akbay e colaboradores $(2003)^{15}$ isolaram quercetina, canferol e isoramnetina da mesma planta. Os resultados obtidos por estes autores reafirmam a positividade para flavonóides obtida neste trabalho.

Conforme Özen e Korkmaz (2003) ${ }^{16}$ vários metabólitos diferentes já foram identificados em U. dióica, entre eles: glicopiranosideos, glicoproteínas, proteínas, flavonóides glicosilados, carotenóides, bem como compostos biologicamente ativos, tais como aminoácidos, ácido cafeico, ácido málico e ácido quínico, óleos essenciais, ácido fórmico e acético, histamina, taninos, mucilagem, vitaminas (A, B1, B2, C, K1, ácido fólico). Estes metabólitos podem contribuir para os efeitos observados no uso popular das plantas da família Urticaceae.

As mucilagens possuem ação laxativa, atuando também como antidiarréicos, devido à sua natureza coloidal, impedindo a ação de substancias irritantes e até de bactérias sobre a mucosa. Aos heterosídeos flavonoídicos são atribuídas propriedades antitumorais, antiinflamatórias, antioxidante e antivirais. As saponinas apresentam atividades anti-helmintica, ictiotoxica, hipocolesteriolemiante e anti-inflamatória descritas na literatura, bem como os taninos que apresentam atividade contra o reumatismo, problemas renais e processos inflamatórios em geral. As purinas podem apresentar efeitos sobre o sistema nervoso central e sistema cardiovascular, entre outros ${ }^{17}$. Tendo em vista as ações farmacológicas descritas na literatura para estes metabólitos, esta planta é promissora para mais estudos que comprovem sua atividade analgésica e anti-inflamatória. 


\section{Conclusão}

A quantificação de polifenóis totais, flavonóides, taninos condensados e alcalóides, bem como a análise da capacidade antioxidante nas raízes da planta foram descritas pela primeira vez na literatura neste trabalho. Este estudo que determinou o perfil fitoquímico da casca e do miolo da raiz de $U$. baccifera caracterizou-se positivo para vários testes realizados, o que levou a uma maior clareza a respeito das classes de metabólitos secundários presentes na raiz. Além disso, permitiu evidenciar diferenças qualitativas nos resultados de purinas, heterosídeos flavonoídicos e heterosídeos saponinicos. Essa espécie apresenta seu uso popular nesta região principalmente como anti-inflamatória e para o tratamento de infecções micóticas da pele, o que pode estar relacionado com a atividade das substâncias encontradas nesta análise.

\section{Agradecimentos}

Ao Centro Universitário Franciscano por ceder sua estrutura para a realização das análises fitoquímicas e pela formação dada aos profissionais que elaboraram este trabalho. A UFSM e ao Programa de Pós-Graduação Ciências Farmacêuticas pela realização dos doseamentos complementares.

\section{Referências Bibliográficas}

1 - Maciel MAM, Pinto AC, Veiga Jr VF, Grynberg NF, Echevarria, A. Plantas Medicinais: A Necessidade de Estudos Multidisciplinares. Quím Nova. 2002; 25(3):429-38.

2 - Joly, AB. Botânica: Introdução a Taxonomia Vegetal. 12a ed. São Paulo: Companhia Editora Vegetal; 1998.

3 - Badilla B, Mora G, Lapa AJ, Emim JAS. Anti-inflammatory activity of Urera baccifera (Urticaceae) in SpragueDawley rats. Rev Biol Trop. 1999; 47(3):365-71.

4 - Martins FA, Gomes MM da R, Nogueira FLP, Martins GR, Romanos MTV, Kaplan MAC, et al. In vitro inhibitory effect of Urera baccifera (L.) Gaudich. Extracts against herpes simplex. Afr J Pharm Pharmacol. 2009; 3(11):581-4

5 - Choi, CW, Kim, SC, Hwang, SS, Choi, BK, Ahn, HJ, Lee, MY, et al. Antioxidant activity and free radical scavenging capacity between Korean medicinal plants and flavonoid by assay-guided comparision. Plant Science. 2002; 163:1161-8.

6 - Chandra, S, Mejia, EG. Polyphenolic compounds, antioxidant capacity and quinone reductase activity of an aqueous extract of Ardisia compressa in comparision to Mate (llex paraguaiensis) and Green (Camellia sinensis) Teas. J Agric Food Chem. 2004; 52:3583-9.

7 - Woisky, RG, Salatino, A. Analysis of própolis: some parameters and procedures for chemical quality control. J Apic Res. 1998; . 37(2):99-105.

8 - Morrison, IM, Asiedu, EA, Stuchbury,T, Powell, AA. Determination of lignin and tannin contents of Cowpea seed coats. Ann Bot. 1995; 76 (3):287-290

9 - Oliveira, MAC, Albuquerque, MM, Xavier, HS, Strattmann, RR, Grangeiro Junior, S, Queiroz, AT. Desenvolvimento e validação de metodologia para quantificação de alcalóides totais como berberina em fitoterápico contendo Berberis vulgaris L. Rev Bras Farmacogn. 2006; 16 (3):357-64

Saúde (Santa Maria), v.36, n.2, p. 63-70,

jul./dez. 2010.

Análise fitoquímica qualitativa das cascas e do miolo da raíz de urera baccifera (l.) gaudich (urticaceae)
10 - Moreira EA. Contribuição para o estudo fitoquímico de Lobelia hassleri A. ZAHLB e Lobelia stellfeldii R. Braga. Companulaceae. Trib Farm. 1979; 47(1):13-39.

11 - Martins, GR, Nogueira, FLP, Menezes, FS, Kaplan, MAC. Atividade antioxidante do extrato etanólico e suas partições obtidas dos galhos de Urera baccifera Gaudich. Através do ensaio com DPPH. $29^{a}$ Reunião Anual da 
Sociedade Brasileira de Química, 2006.

12 - Mannion, F e Menezes, FS. Antioxidant activity of Urera baccifera Gaud extracts. The Trinity College Dublin Journal of Pharmacy \& Pharmaceutical Sciences. 2010; 2(1):8-9

13 - Boligon, AA, Feltrin, AC, Janovik, V, Frohlich, JK, Athayde, ML. Estudo fitoquímico das cascas do tronco de Scutia buxifolia Reissek. Saúde, 2009; 35(2):4-6.

14 - Chaurasia, N. \& Wichtl, M. Flavonolglykoside aus Urtica dioica. Planta Med. 1987:432-4.

15 - Akbay, P., Basaran, A.A., Undeger, U., Basaran, N. In vitro immunomodulatory activity of flavonoid glycosides from Urtica dioica L. Phytotherapy Research. 2003; 17:34-7.

16 - Özen T., Korkmaz H. Modulatory effect of Urtica dioica L. (Urticaceae) leaf extract on biotransformation enzyme systems, antioxidant enzymes, lactate dehydrogenase and lipid peroxidation in mice. Phytomedicine. 2003; 10:405-15.

17 - Simões CMO, Schenkel EP, Gosmann G, Mello JCP, Mentz LA, Petrovick PR., organizadores. Farmacognosia: da planta ao medicamento. 6 ed, 1 reimp. Porto Alegre / Florianópolis: Editora da UFRGS / Editora UFSC; 2010.

\section{Endereço para correspondência}

Amanda Leitão Gindri - Rua Benjamin Constant, n 930, apto 114. Santa Maria, RS. CEP 97.050-020 Telefones: (55) 3317 - 7163 e (55) 9653 - 7163

E-mail: amandagindri@terra.com.br

Recebido em 02 de março de 2011.

Aprovado em 12 de junho de 2011. 